\title{
Upper Digestive Lesions Not Linked to Portal Hypertension during Cirrhosis: About 82 Cases in the Hepato-Gastroenterology Department of Aristide Le Dantec Hospital
}

\author{
Mamadou Ngoné Gueye ${ }^{1 *}$, Marie Louise Bassène' ${ }^{2}$, Salamata Diallo², Marème Polele Fall2, \\ Cheikh Ahmadou Bamba Cissé2, Mame Aïssé Thioubou, Gnagna Diouf1, Daouda Dia1, \\ Mouhamadou Mbengue1, Mamadou Lamine Diouf ${ }^{2}$ \\ ${ }^{1}$ Hoppital Général Idrissa Pouye (HOGIP), Dakar, Sénégal \\ ${ }^{2}$ Hoppital Aristide Le Dantec (HALD), Dakar, Sénégal \\ ${ }^{3}$ Hopital de la Paix, Ziguinchor, Sénégal \\ Email: *mamadoungone@yahoo.fr
}

How to cite this paper: Gueye, M.N., Bassène, M.L., Diallo, S., Fall, M.P., Cissé, C.A.B., Thioubou, M.A., Diouf, G., Dia, D., Mbengue, M. and Diouf, M.L. (2020) Upper Digestive Lesions Not Linked to Portal Hypertension during Cirrhosis: About 82 Cases in the Hepato-Gastroenterology Department of Aristide Le Dantec Hospital. Open Journal of Gastroenterology, 10, 53-60.

https://doi.org/10.4236/ojgas.2020.104006

Received: February 18, 2020

Accepted: March 30, 2020

Published: April 2, 2020

Copyright $\odot 2020$ by author(s) and Scientific Research Publishing Inc. This work is licensed under the Creative Commons Attribution International License (CC BY 4.0).

http://creativecommons.org/licenses/by/4.0/ (c) (i) Open Access

\begin{abstract}
Introduction: The aim of this study was to determine the frequency of digestive lesions unrelated to portal hypertension during cirrhosis and to look for a possible correlation between these lesions and the severity of chronic liver disease. Material and method: Over a period of 15 months (April 1, 2014 to June 30,2015), all the records of cirrhotic patients who followed up on an outpatient or inpatient basis in the hepato-gastroenterology department of the Aristide Le Dantec Hospital were collected. The data collected were as follows: age, sex, Child-Pugh severity score, etiology of cirrhosis, indication for endoscopy and endoscopic lesions observed. Results: Data were analyzed from 82 patient records with a mean age of 43 years (range 16 and 79 years) and a sex ratio of 1.4 (54 males). Cirrhosis was classified as Child-Pugh B in $47 \%$ of cases and Child-Pugh C in 35\% of cases. The etiology was viral B in 75 patients (91.5\%), B-D co-infection in 2 cases, and alcoholic in 1 case. The indication for oeso-gastroduodenal endoscopy was a systematic search for signs of portal hypertension in 66 cases (80.4\%), upper gastrointestinal haemorrhage in 11 cases (13.4\%) and epigastralgia in $6.2 \%$ of cases. Endoscopic lesions unrelated to portal hypertension were observed in 61 patients (74.4\%). Peptic ulcer was present in 26 patients (31.7\%), and congestive gastrobulbitis was observed in 38 patients (46.3\%) and erosive gastrobulbitis in 32 patients (39\%). Of the 43 upper GI endoscopies with biopsies, Helicobacter pylori was found at histology in 17 cases (39.5\%). Eighteen patients (21.9\%) had esophageal candidiasis. In multivariate analysis, there was no association be-
\end{abstract}


tween no portal hypertension lesions and the severity of cirrhosis. Conclusion: Upper gastro intestinal lesions unrelated to hypertension were present in $3 / 4$ of cirrhotic patients. Peptic ulcer disease and congestive and erosive gastrobulbitis were the most frequently observed lesions. There was no significant association between non-PTH-related lesions and the severity of cirrhosis.

\section{Keywords}

Cirrhosis, Peptic Ulcer, Congestive Gastrobulbite, Erosive Gastrobulbite

\section{Introduction}

Portal hypertension is one of the major complications of cirrhosis. It is defined by an increase in pressure in the portal system. It is estimated indirectly by a portal or hepatic pressure gradient greater than $5 \mathrm{mmHg}$.

The increase in hepatic venous pressure gradient (HVPG) leads to the formation of portosystemic collateral veins (nasogastric varices, esophageal varices, gastric varices) and structural changes in the gastric mucosa (congestive gastropathy, antral vascular ectasia) [1] [2] [3].

Upper gastrointestinal lesions unrelated to portal hypertension are defined by all abnormalities of the esophago-gastroduodenal mucosa other than varicose veins, portal hypertension gastropathy and antral vascular ectasia.

Because of their frequency and severe prognosis, portal hypertension lesions have been the subject of much work both diagnostically and therapeutically. On the other hand, apart from studies on the association between peptic ulcer disease and cirrhosis, few data are available on upper digestive lesions unrelated to portal hypertension during cirrhosis. It is clearly established in many studies that the prevalence of peptic ulcer disease is higher in cirrhotic patients than in the general population; however, the relationship between Helicobacter pylori ( $H$. pylori) infection and peptic ulcer disease in cirrhosis remains controversial.

Similarly, a high incidence of hemorrhagic complications of peptic ulcer disease in cirrhotic patients has been reported in the literature, increasing the risk of death in this fragile field [4] [5] [6]. At a time when the deleterious role of proton pump inhibitor (PPI) use in the occurrence of ascites liquid infection in cirrhotic patients is increasingly reported in the literature [7], we deemed it necessary to undertake this study with the general objective of determining the frequency of upper gastrointestinal lesions unrelated to portal hypertension during cirrhosis and to investigate a possible correlation between these lesions and the severity of chronic hepatopathy.

\section{Patients and Methods}

We conducted a retrospective, descriptive and analytical study from April 1, 2014 to June 30, 2015. All the records of cirrhotic patients, whether followed as outpatients or hospitalized in the hepato-gastroenterology department were collected. 
The diagnosis of cirrhosis was based on a combination of clinical and paraclinical arguments.

$\varnothing$ Clinics

Liver atrophy, hepatomegaly with a sharp lower edge and anterior surface irregular, signs of portal hypertension (abdominal collateral venous circulation, ascites, splenomegaly), clinical signs of hepatocellular insufficiency.

$\varnothing$ Biological

Cytolysis, cholestasis, hepatocellular insufficiency; beta-gamma block on serum protein electrophoresis.

$\varnothing$ Ultrasound

Hepatic dysmorphia and/or diffuse heterogeneity of the parenchyma associated or not with signs of portal hypertension (ascites, splenomegaly, collateral venous circulation, dilatation of the portal vein and reversal of portal flow).

\section{$\varnothing$ Endoscopic}

The presence of signs of portal hypertension (esophageal and/or gastric varices, portal hypertension gastropathies, vascular ectasias).

The endoscopically visualized esophageal-gastroduodenal lesions were all recorded. These lesions were classified into 2 groups: those related to portal hypertension (varicose veins, portal hypertension gastropathy and antral vascular ectasia) and those independent of portal hypertension (all anomalies of the oeso-gastroduodenal mucosa apart from those mentioned above).

In addition to digestive lesions, the following data were collected: age, sex, Child-Pugh severity score, etiology of cirrhosis, indication for endoscopy.

Data were entered into Excel 2007 spreadsheets and analysed using Sphinx version 5 software. Variable comparisons were made using standard Chi 2 and Fisher tests.

The significance threshold was set at $\mathrm{p}<0.05$ for these two statistical tests.

\section{Resultats}

A total of 82 files were collected. The prevalence of cirrhosis was $4.7 \%$. The mean age was 43 years, with extremes of 16 and 79 years. The age range of 20 - 50 years represented $78 \%$ of the population. The sample consisted of 48 men (58\%) with a sex ration of 1.4.

Cirrhosis was classified as Child Pugh B in $47 \%$ of cases, Child Pugh C and Child Pugh A in $35 \%$ and $18 \%$ of cases respectively.

The etiology of cirrhosis was viral B in 75 patients (91.5\%), B-D co-infection in 2 cases, alcoholic in 1 case. In 3 patients, the etiology was unknown.

The indication for oesophageal-gastroduodenal endoscopy was the systematic search for signs of portal hypertension in 66 cases $(80.4 \%)$, digestive haemorrhage in 11 cases (13.4\%); epigastralgia in 5 cases (6.2\%).

Upper gastrointestinal endoscopy found evidence of portal hypertension in 77 patients (94\%). Endoscopic lesions unrelated to portal hypertension were observed in 61 patients $(74.4 \%)$, including peptic ulcers in 26 patients $(31.7 \%)$, 
congestive gastrobulbitis in 28 patients (34.1\%), erosive gastrobulbitis in 32 cases (39\%) and atrophic fundic gastritis in 13 cases (15.8\%).

Table 1 shows the endoscopic lesions not related to portal hypertension that were objectified and Figure 1 shows the frequency of some of these lesions as a function of the child-Pugh score.

Of the 43 upper gastrointestinal endoscopies with biopsy, Helicobacter pylori was found in histology in 17 cases (39.5\%). The endoscopic lesions that motivated the biopsy were gastric ulcer in 10 cases $(H$. pylori positive in 4$)$, erosive gastritis in 22 cases (Hp positive in 9 ), atrophic gastritis in 4 cases ( $H$. pylori

Table 1. Summary table of upper gastrointestinal lesions not related to portal hypertension.

\begin{tabular}{|c|c|c|}
\hline Endoscopic Lesion & Number of patient & Percentage \\
\hline Esophageal candidiasis & 18 & 21.9 \\
\hline Peptic esophagitis & 8 & 9.7 \\
\hline -Grade A Los Angeles & 2 & 2.4 \\
\hline -Grade B Los Angeles & 3 & 3.6 \\
\hline -Grade C Los Angeles & 3 & 3.6 \\
\hline Schatzki Ring & 3 & 3.6 \\
\hline Hiatal hernia & 9 & 10.9 \\
\hline Gastric ulcer & 12 & 14.6 \\
\hline -Antrum & 8 & 9.7 \\
\hline -Angulus & 4 & 4.8 \\
\hline Duodenal ulcer & 14 & 17.1 \\
\hline -Anterior face bulb & 8 & 9.7 \\
\hline -Back side bulb & 1 & 1.2 \\
\hline -Roof of the bulb & 3 & 3.6 \\
\hline -Floor of the bulb & 2 & 2.4 \\
\hline Congestive gastro-bulbite & 28 & 34.1 \\
\hline Erosive gastro-bulbite & 32 & 39 \\
\hline Atrophic fundic gastritis & 13 & 15.8 \\
\hline
\end{tabular}

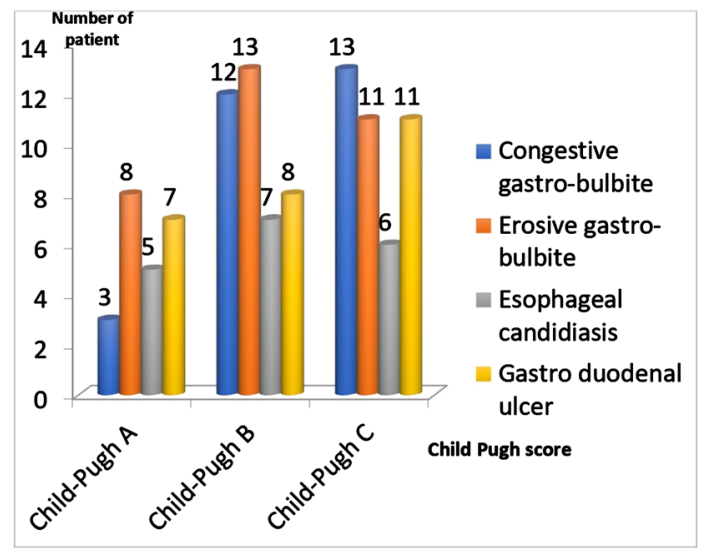

Figure 1. Frequency of some of upper gastrointestinal lesions not related to portal hypertension as a function of the child-Pugh score. 
positive in 1) and gastritis congestive and erythematous in 7 cases (H. pylori positive in 3). eighteen patients (21.9\%) had esophageal candidiasis.

In multivariate analysis, there was no association between these no portal hypertension lesions and the severity of cirrhosis (Table 2).

\section{Discussion}

The retrospective nature of our study and the small sample size are limitations of our study.

Upper GI endoscopy found lesions unrelated to portal hypertension in 61 patients $(74.4 \%)$. The most frequent lesions were peptic ulcer and congestive or erosive gastrobulbitis observed in $31.7 \%, 31.4 \%$ and $39 \%$ of cases, respectively.

There was no significant association between the frequency of these lesions and the severity of cirrhosis. We found no studies in Africa reporting the prevalence of these lesions unrelated to portal hypertension during cirrhosis.

In Italy, Sacchetti et al. reported a $29.6 \%$ prevalence of erosive gastrobulitis and $27.2 \%$ prevalence of peptic ulcers in cirrhotic patients [5].

Dong J K et al. in Korea and Chen L S et al. in China reported a prevalence of peptic ulcers of $31.3 \%$ and $25.4 \%$ respectively [4] [8]. In these different studies, the frequency of peptic ulcer lesions not related to portal hypertension was significantly higher in the cirrhotic group than in the control group. As we objectified in our study, these lesions were independent of the severity of cirrhosis. Given these high prevalences of peptic ulcers and gastrobulbites in cirrhotic patients, it is important to study the role of $H$. pylori in the development of these peptic lesions.

The search for Helicobacter pylori was positive in 17 cases out of the 43 biopsies performed in our study (39.5\%). This relatively low prevalence of $H$. pylori infection in our study could be explained by the fact that more than $70 \%$ of cirrhotic patients were at stage B or C of the Child-Pugh classification. Most of these patients took prolonged antibiotic therapy as part of primary or secondary prevention of spontaneous ascites fluid infection.

Table 2. Association between upper gastrointestinal lesions unrelated to portal hypertension and the severity of cirrhosis.

\begin{tabular}{cccccc}
\hline Endoscopic Lesion & Child A & Child B & Child C & Percentage & p value \\
\hline Esophageal candidiasis & 5 & 7 & 6 & 21.9 & 0.8 \\
Peptic esophagitis & 3 & 4 & 1 & 9.7 & 0.2 \\
Schatzki Ring & 1 & 2 & 0 & 3.6 & 0.7 \\
Hiatal hernia & 2 & 4 & 3 & 10.9 & 0.6 \\
Gastric ulcer & 4 & 3 & 5 & 14.6 & 0.6 \\
Duodenal ulcer & 3 & 5 & 6 & 17.1 & 0.2 \\
Congestive gastro-bulbite & 3 & 12 & 13 & 34.1 & 0.1 \\
Erosive gastro-bulbite & 8 & 13 & 11 & 39 & 0.2 \\
Atrophic fundic gastritis & 4 & 7 & 2 & 15.8 & 0.4
\end{tabular}


Dong J K et al. found histological prevalences of $H$. pylori of $35.1 \%, 62.4 \%$ and 73.7\% respectively in cirrhotic patients, patients with non-ulcerative dyspepsia and those with peptic ulcer disease alone [7]. In China, the prevalence of $H . p y$ lori was $56.2 \%$ in cirrhotics with peptic ulcer disease versus $52.9 \%$ in cirrhotics alone $(\mathrm{p}>0.05)[8]$.

Thus, it would appear that peptic ulcer and gastrobulbites are more frequent in cirrhotics; however, the prevalence of Helicobacter pylori in the latter is comparable or even lower than in non-cirrhotic patients.

Given the low prevalence of $H$. pylori contrasting with the high frequency of gastroduodenal lesions in cirrhotics, it is very likely that other determinants besides $H$. pylori are involved in the development of these lesions in this population.

The etiology of cirrhosis has been suggested as a factor in the occurrence of peptic ulcer and gastrobulbitis during cirrhosis [9]. However, the sample size of our study, particularly in relation to non-viral B aetiologies, does not allow us to apprehend this association. Dong J K et al. estimated the prevalence of peptic ulcer disease to be $42.5 \%$ in patients with viral cirrhosis versus $22 \%$ in patients with alcoholic cirrhosis $(\mathrm{p}<0.001)[4]$.

Hypertensive gastropathy, decreased prostaglandins, disturbances in gastric acid secretion, and increased serum gastrin concentration are incriminated factors in the occurrence of gastroduodenal lesions in cirrhotics; however, the role of these factors is controversial [9] [10].

Apart from gastroduodenal lesions, esophageal lesions, particularly infectious ones, were found. Candidiasis was the most common esophageal lesion. It was objectified in 18 patients (21.9\%). Contrary to the association between esophageal candidiasis and human immunodeficiency virus HIV, very few data are available on esophageal candidiasis during cirrhosis.

Zilberfajn et al. reported a prevalence of invasive candidiasis (candidemia and/or peritoneal candidiasis) of $10.8 \%$ during cirrhosis. The presence of cirrhosis was found to be a risk factor for invasive candidiasis with an OR of 3.5 (1.7 6.7) $(\mathrm{p}<3-10)[11]$.

Cirrhotics present a lymphocyte lineage disorder that occurs in particular within the Peyer's patches. They also have a disorder of the permeability and integrity of the intestinal barrier, which diminishes the defence against and elimination of infectious agents. These abnormalities partly explain the frequency of microbial translocations in these patients, aggravated by the presence of portal hypertension. All of these dysfunctions result in susceptibility to bacterial and fungal infections through translocation and dissemination via the bloodstream and local circulation [11] [12]. Esophageal candidiasis must be adequately managed in cirrhotics, because it is a relative contraindication to ligation of esophageal varices.

These various esophageal-gastroduodenal inflammatory lesions often justify the prescription of proton pump inhibitors. However, the deleterious role of 
proton pump inhibitor intake on the occurrence of ascites liquid infection in cirrhotic patients is suggested in the literature. Hydrochloride is thought to promote intestinal bacterial proliferation and increase intestinal permeability, thereby increasing the risk of bacterial translocation [7]. Given the potential deleterious role of intestinal microbial overgrowth on liver injury that has been suggested by some authors, it is questionable whether greater attention should be paid to PPI prescribing in cirrhotic patients [7].

\section{Conclusion}

The retrospective nature of our study and the small sample size are limitations. However, our study showed that digestive lesions not related to portal hypertension during cirrhosis are very common. They were present in $3 / 4$ of the cases of cirrhosis. Peptic ulcer and congestive and erosive gastrobulbitis were the most frequently observed lesions. There was no significant association between lesions unrelated to portal hypertension and the severity of cirrhosis.

\section{Dedication}

This work is dedicated to Professor Mamadou Lamine Diouf.

\section{Conflicts of Interest}

The authors declare no conflicts of interest regarding the publication of this paper.

\section{References}

[1] Naveau, S., Balian, A., Perlemuter, G., Gerolami, K. and Vons, C. (2003) Abrégés, connaissances et pratiques. Hépato-gastro-entérologie. Masson, Paris, 111-135.

[2] Pilette, C., Croquet, V., Vuillemin, E., Oberti, F. and Cales, P. (1999) Diagnostic précoce et non invasif de la cirrhose du foie. Gastroenterologie Clinique et Biologique, 23, 657-665.

[3] Tsochatzis, E.A., Bosch, J. and Burroughs, A.K. (2014) Liver Cirrhosis. Lancet, 383, 1749-1761. https://doi.org/10.1016/S0140-6736(14)60121-5

[4] Kim, D.J., et al. (2008) H. pylori and Peptic Ulcer in Cirrhosis. The Korean Journal of Internal Medicine, 23, 16-21. https://doi.org/10.3904/ kjim.2008.23.1.16

[5] Sacchetti, C., Capello, M., Rebecchi, P., Roncucci, L., Zanghieri, G., Tripodi, A. and Ponz de Leon, M. (1988) Frequency of Upper Gastrointestinal Lesions in Patients with Liver Cirrhosis. Digestive Diseases and Sciences, 33, 1218-1222. https://doi.org/10.1007/BF01536669

[6] Kitano, S. and Dolgor, B. (2000) Does Portal Hypertension Contribute to the Pathogenesis of Gastric Ulcer Associated with Liver Cirrhosis? Journal of Gastroenterology, 35, 79-86. https://doi.org/10.1007/s005350050018

[7] Goel, G.-A., Deshpande, A. and Lopez, R. (2012) Increased Rate of Spontaneous Bacterial Peritonitis among Cirrhotic Patients Receiving Pharmacologic Acid Suppression. Clinical Gastroenterology and Hepatology, 10, 422-427.

[8] Chen, L.S., Lin, H.C., Lee, F.Y., Hou, M.C. and Lee, S.D. (1995) Prevalence of Duodenal Ulcer in Cirrhotic Patients and Its Relation to Helicobacter pylori and Portal 
Hypertension. Chinese Medical Journal ( Taipei), 56, 226-231.

[9] Fraser, A.G., Pounder, R.E. and Burroughs, A.K. (1993) Gastric Secretion and Peptic Ulceration in Cirrhosis. Journal of Hepatology, 19, 171-182.

https://doi.org/10.1016/S0168-8278(05)80191-6

[10] Cryer, B. and Spechler, S.J. (2006) Peptic Ulcer Disease. In: Felman, M., Friedman, L.S. and Brandt, L.J., Eds., Sleisenger and Fordtran's Gastrointestinal and Liver Disease, 8th Edition, Saunders, Philadelphia, 1089-1110.

[11] Zilberfajn, C., Lobo, D. and Annonay, M. (2014) La cirrhose: Un facteur de risque de candidose invasive méconnue. Annales Françaises d Anesthésie et de Réanimation, 33, A110. https://doi.org/10.1016/j.annfar.2014.07.182

[12] Poitras, P., Dumont, A., Dubé, S. and Galmiche, J.P. (2014) L'œsophage. In: L'appareil digestif des sciences fondamentales à la Clinique, 2nd Edition, University of Montreal Press, Montréal, 11-32. 